\title{
HUBUNGAN PELAKSANAAN SUPERVISI DAN MOTIVASI KERJA GURU DENGAN KEMAMPUAN PEMBELAJARAN GURU SMA IT ASSALAM MARTAPURA
}

\author{
Ngalimun \\ Universitas Muhammadiyah Banjarmasin \\ email: alim.pbsid@yahoo.com
}

\begin{abstract}
ABSTRAK
Rancangan penelitian ini bertujuan untuk mendapatkan gambaran yang jelas mengenai hubungan pelaksanaan supervisi, motivasi kerja guru dan kemampuan pembelajaran guru SMA IT Assalam Martapura. Dalam penelitian ini peneliti hanya mengukur variabel yang ada tanpa memanipulasinya. Pada salah satu sisi penelitian ini menggunakan metode penelitian deskriptif, maksudnya adalah mendeskripsikan suatu fenomena seperti apa adanya, tidak ada perlakuan yang diberikan pada subyek seperti penelitian eksperimen. Pada sisi lain ditinjau dari segi masalah dan tujuan penelitian, penelitian ini menggunakan teknik korelasional. Tehnik korelasional adalah penelitian yang sifatnya melukiskan hubungan yang terdapat antara dua variabel atau lebih. Penelitian korelasional berusaha menetapkan seberapa kuatnya hubungan yang terdapat antara dua variabel.
\end{abstract}

Kata Kunci: Supervisi dan Motivasi, Kemampuan Pembelajaran

\section{ABSTRACT}

This research design aims to get a clear picture of the relationship between the implementation of supervision, teacher work motivation and learning abilities of SMA IT Assalam Martapura teachers. In this study, researchers only measure the existing variables without manipulating them. On the one hand, this research uses descriptive research methods, the intention is to describe a phenomenon as it is, there is no treatment given to the subject such as experimental research. On the other hand, in terms of problems and research objectives, this study uses correlational techniques. Correlational technique is research that describes the relationship that exists between two or more variables. Correlational research tries to determine how strong the relationship is between two variables.

Keywords: Supervision and Motivation, Learning Abili 


\section{PENDAHULUAN}

Pendidikan merupakan fenomena manusia yang fundamental, yang juga mempunyai sifat konstruktif dalam hidup manusia. Karena itulah kita dituntut untuk mampu mengadakan refleksi ilmiah tentang pendidikan tersebut, sebagai pertanggung jawaban terhadap perbuatan yang dilakukan, yaitu mendidik dan dididik. (Hasbullah: 2007).

Sekolah tempat pendidikan merupakan kebutuhan dan tuntutan masyarakat yang diharapkan mampu mewujudkan manusia Indonesia seutuhnya yang berkualitas. Untuk memenuhi kebutuhan dan tuntutan tersebut, pendidikan secara formal diselenggarakan disekolah atau Madrasah. Penyelenggaraan pendidikan tersebut tentunya memerlukan pengelolaan untuk mencapai tujuan seperti yang diharapkan. Seperti yang tertuang dalam UndangUndang Republik Indonesia Nomor. 20 Tahun 2003 tentang Sistem Pendidikan Nasional BAB II pasal 3 disebutkan bahwa Pendidikan Nasional berfungsi mengembangkan kemampuan dan membentuk watak serta peradaban bangsa yang bermartabat dalam rangka mencerdaskan kehidupan bangsa. Bertujuan untuk berkembangnya potensi peserta didik agar menjadi manusia yang beriman dan bertaqwa kepada Tuhan Yang Maha Esa, berakhlak mulia, sehat, berilmu, cakap, kreatif, mandiri, dan menjadi warga negara yang demokratis serta bertanggung jawab.

Untuk mewujudkan sekolah yang berkualitas, akan sangat tergantung pada pengelolaan sekolah. Pengelolaan sekolah yang sepenuhnya diatur oleh kapala sekolah yang diberi otonomi dalam pengelolaan sekolahnya. Kepala sekolah harus memiliki integritas dan kepemimpinan yang kuat dalam mengelola sekolahnya. Kepala Sekolah sebagai supervisor dituntut untuk aktif dan kreatif menumbuhkan inovasi-inovasi baru yang lebih positif dalam rangka menjawab tuntutan dan perkembangan dunia pendidikan serta lebih khusus lagi menghadapi era otonomisasi yang nantinya berdampak pada pelaksanaan otonomi pendidikan.

Supervisi merupakan salah satu tugas kepala sekolah yang sasarannya adalah meningkatkan kinerja guru dalam melaksanakan pengajaran. Melalui pelaksanaan supervisi yang efektif, superisor dapat mengontrol, membina, mendorong dan memotivasi guru-guru untuk melaksanakan tugasnya yang lebih berkualitas. Namun berdasarkan kenyataan yang ada, kegiatan supervisi belum dilaksanakan secara efektif, baik dalam mekanisme pelaksanaan, implementasi dari hasil supervisi, maupun dalam hal kemampuan atau profesionalisme dari pelaksana/supervisor.

Kepala sekolah sebagai supervisor harus mampu memiliki kemampuan dalam membangkitkan motivasi para guru dan staf lainnya sebab motivasi merupakan tenaga pendorong atau penarik yang menyebabkan adanya tingkah laku kearah tujuan tertentu. Mengacu pada hal tersebut bahwa motivasi merupakan bagian yang sangat penting dalam sekolah, agar para pendidik dengan sungguh-sungguh memiliki kemampuan yang tinggi dalam melaksanakan tugas dan pekerjaannya. Dengan motivasi yang tinggi, maka sekolah akan mampu meraih prestasi yang diinginkan. Oleh karenanya, Kepala Sekolah dituntut memiliki kemampuan membangkitkan motivasi para pegawai sehingga kinerja mereka meningkat.

Salah satu faktor utama yang menentukan mutu pendidikan adalah guru. Gurulah yang berada di garda terdepan dalam menciptakan kualitas sumber daya manusia. Guru berhadapan langsung dengan para peserta didik di kelas melalui proses belajar mengajar. Di tangan gurulah akan dihasilkan peserta didik yang berkualitas, baik secara akademis, skill (keahlian), kematangan emosional, dan moral serta spiritual. Dengan demikian, akan dihasilkan generasi masa depan yang siap hidup dengan tentangan zamannya. Oleh karena itu, diperlukan sosok guru yang mempunyai kualitas, kompetansi, dan dedikasi yang tinggi dalam menjalankan tugas profesionalnya.

Perubahan kurikulum yang menekankan pada kompetensi, guru memegang peranan penting terhadap implementasi KTSP dan K-13, karena gurulah yang pada akhirnya akan melaksanakan kurikulum di dalam kelas. Guru adalah kurikulum berjalan. Menurut mantan Menteri Pendidikan dan Kebudayaan Fuad Hasan, sebaik apa pun kurikulum dan sistem pendidikan yang ada, tanpa didukung oleh mutu guru yang memenuhi syarat, maka semuanya akan sia-sia. Peningkatan mutu pendidikan di Indonesia tidak cukup dengan pembenahan di bidang kurikulum saja, tetapi harus juga diikuti dengan peningkatan mutu guru dijenjang tingkat dasar dan menengah. Tanpa upaya meningkatkan mutu guru, semangat tersebut tidak akan mencapai harapan yang diinginkan.

\section{METODE PENELITIAN}

Rancangan dalam penelitian berdasarkan sifat masalah dan tujuan penelitian adalah menggunakan rancangan deskriptif korelasi, karena mengkaji dan memecahkan permasalahan sekarang yang dihadapi dan mempunyai tujuan untuk 
memperoleh ada tidaknya hubungan antara dua atau beberapa variabel tentang suatu keadaan tertentu (Suharsimi Arikunto: 2005). Metode ini digunakan dalam rangka memaparkan dan menggambarkan , menganalisis serta menafsirkan data dari variabel kegiatan pelaksanaan supervisi, motivasi kerja guru dengan kemampuan pembelajaran guru SMA IT Assalam Martapura. Pendekatan kualitatif ini bertitik tolak dari anggapan bahwa semua gejala hasil pengamatan dapat diukur dalam bentuk angka sehingga memungkinkan digunakan teknik-teknik analisis statistik (Sugiana, 2006:8).

Selanjutnya Suharsimi Arikunto $(2005 ; 236)$ mengatakan bahawa penelitian deskriptif adalah penelitian yang mempunyai tujuan untuk memecahkan masalah yang ada pada masa sekarang dan bersifat tidak terbatas pada pengumpulan dan penyusunan data saja melainkan sampai kepada kegiatan analisis dan interprestasi data. Metode penelitian deskriptif dibedakan atas empat jenis : (1) penelitian kasus; (2) kausal komparatif; (3) korelasi; dan (5) survey.

Rancangan penelitian ini bertujuan untuk mendapatkan gambaran yang jelas mengenai hubungan pelaksanaan supervisi, motivasi kerja guru dan kemampuan pembelajaran guru SMA IT Assalam Martapura. Dalam penelitian ini peneliti hanya mengukur variabel yang ada tanpa memanipulasinya. Pada salah satu sisi penelitian ini menggunakan metode penelitian deskriptif, maksudnya adalah mendeskripsikan suatu fenomena seperti apa adanya, tidak ada perlakuan yang diberikan pada subyek seperti penelitian eksperimen (Furhan, 1982:50). Pada sisi lain ditinjau dari segi masalah dan tujuan penelitian, penelitian ini menggunakan teknik korelasional. Tehnik korelasional adalah penelitian yang sifatnya melukiskan hubungan yang terdapat antara dua variabel atau lebih. Penelitian korelasional berusaha menetapkan seberapa kuatnya hubungan yang terdapat antara dua variabel (Arikunto, 1998: 8081)

\section{HASIL PENELITIAN}

Deskripsi Pelaksanaan Supervisi SMA IT Assalam Martapura

Sesuai dengan angket, rekapitulasi seluruh data secara lengkap tentang orientasi/pelaksanaan supervisi kepala SMA IT Assalam Martapura dapat dilihat pada lampiran. Deskripsi data tentang pelaksanaan supervisi kepala sekolah yang digunakan berdasarkan hasil angket dari beberapa guru SMA IT Assalam Martapura dengan perhitungan prosentase (\%) adalah sebagai berikut:
Data variabel pelaksanaan supervisi kepala sekolah mempunyai rentang skor empiris sebesar 28 dari 172 sampai dengan 200. Rata-rata $(\mathrm{M})=$ 182,6 , dengan simpangan baku $(\mathrm{SD})=5,94$, median $(\mathrm{Me})=182,00$, dan modus $(\mathrm{Mo})=181,00$. Banyak kelas yang ditetapkan dalam penelitian ini terdiri dari 4 kelas dengan panjang kelas 7 .

Tabel: Distribusi Frekuensi Skor Pelaksanaan Supervisi

\begin{tabular}{|c|c|c|c|}
\hline No. & Interval Kelas & Frekuensi & $\begin{array}{c}\text { Frekuensi } \\
\text { Relatif }(\%)\end{array}$ \\
\hline 1 & $172-178$ & 17 & 25,0 \\
\hline 2 & $179-185$ & 33 & 48,5 \\
\hline 3 & $186-192$ & 14 & 20,6 \\
\hline 4 & $193-200$ & 4 & 5,9 \\
\hline & J u m l a h & $\mathbf{6 8}$ & $\mathbf{1 0 0 , 0}$ \\
\hline
\end{tabular}

Sumber : data primer di olah (2020)

Dari tabel 1. di atas menunjukkan frekuensi terbanyak ada pada interval kelas 179-185 dengan jumlah sebesar 33 orang atau 48,5\%, sedangkan frekuensi paling kecil berada pada interval kelas 193-200 dengan jumlah sebesar 4 orang atau 5,9\%.

Dengan mengacu pada kerangka teori tentang pengkategorian yang telah ditetapkan di bab 3 yakni untuk skor $>(\mathrm{Mi}+\mathrm{Sdi})=$ tinggi, skor antara $(\mathrm{Mi}-\mathrm{Sdi})$ s.d $(\mathrm{Mi}+$ sdi $)=$ sedang dan $(\mathrm{Mi}-\mathrm{Sdi}) \mathrm{ke}$ bawah $=$ rendah , maka dalam penelitian ini diperoleh :

Jumlah item pertanyaan 42 buah, pilihan jawaban 1 s.d 5 . Nilai tertinggi ideal $=42 \times 5=210$

Nilai terendah $\quad=42 \times 1=42$

Mi $\quad=1 / 2($ nilai ideal tertinggi + nilai terendah $)$

$=1 / 2(210+42)$

$=126$

Sdi $=1 / 6$ (nilai ideal tertinggi - nilai terendah $)$

$=1 / 6(210-42)$

$=28$

$\mathrm{Mi}+\mathrm{Sdi}=126+28=154$

$\mathrm{Mi}-\mathrm{Sdi}=126-28=98$

Pengelompokan skor pelaksanaan supervisi dapat dilihat pada tabel berikut :

Tabel 4.2 Pengelompokan Skor Pelaksanaan Supervisi

\begin{tabular}{|l|l|l|l|l|}
\hline No. & Interval & $\mathrm{f}$ & Prosentase & Keterangan \\
\hline 1 & 154 ke atas & 68 & 100 & Tinggi \\
2 & 98 s.d 154 & 0 & 0 & Sedang \\
3 & 98 ke bawah & 0 & 0 & Rendah \\
\hline & Jumlah & 68 & 100 & \\
\hline
\end{tabular}

Berdasarkan perhitungan di atas skor variabel pelaksanaan supervisi didapat sebanyak 68 sampel $(100 \%)$ berkategori tinggi, sehingga dapat disimpulkan secara umum bahwa pelaksanaan supervisi SMA IT Assalam Martapura tergolong tinggi. 


\section{Pelaksanaan Supervisi}

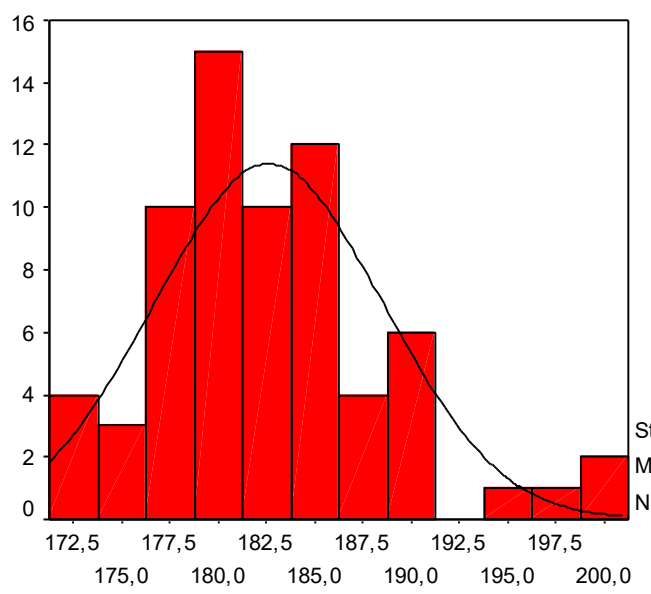

Pelaks anaan Supervisi

Grafik: Distribusi skor pelaksanaan supervisi

Supervisi adalah bantuan yang diberikan untuk memperbaiki situasi belajar mengajar yang lebih baik. Supervisi adalah suatu usaha menstimulasi, mengkoordinasi dan membimbing secara kontinu pertumbuhan guru-guru di sekolah baik secara individu maupun secara kolektif, agar lebih mengerti dan lebih efektif dalam mewujudkan seluruh fungsi pengajaran.

Berdasarkan pengujian hipotesis hubungan pelaksanaan supervisi dengan kemampuan pembelajaran guru SMA IT Assalam Martapura diperoleh diperoleh terdapat hubungan yang positif dan signifikan antara pelaksanaan supervisi dengan kemampuan pembelajaran guru dengan koefesien korelasi $\mathrm{r}=0,555$.

Atas dasar hasil pengujian hipotesis tersebut dapat diartikan bahwa jika pelaksanaan supervisi di sekolah berjalan baik/tinggi maka akan berakibat juga pada tingginya kemampuan pembelajaran guru SMA IT Assalam Martapura dan sebaliknya.

\section{Deskripsi Motivasi Kerja Guru.}

Data variabel motivasi kerja guru berdasarkan hasil pengolahan dan analisis data disimpulkan hasil penelitian di SMA IT Assalam Martapura memperlihatkan skor sebagai berikut.:

Data variabel motivasi kerja guru mempunyai rentang skor empiris sebesar 15 dari 118 sampai dengan 133 . Rata-rata $(M)=127,14$, dengan simpangan baku (SD) $=3,48$ median $(\mathrm{Me})$ $=128$, dan modus $(\mathrm{Mo})=129,00$. Banyak kelas yang ditetapkan dalam penelitian ini terdiri dari 4 kelas dengan panjang kelas 4.
Tabel: Distribusi Frekuensi Skor Motivasi Kerja Guru

\begin{tabular}{|l|c|c|c|}
\hline No. & $\begin{array}{c}\text { Interval } \\
\text { Kelas }\end{array}$ & $\begin{array}{c}\text { Frekuensi } \\
\text { Absolut }\end{array}$ & Frekuensi Relatif (\%) \\
\hline 1 & $118-121$ & 6 & 8,8 \\
\hline 2 & $122-125$ & 13 & 19,1 \\
\hline 3 & $126-129$ & 30 & 44,1 \\
\hline 4 & $130-133$ & 19 & 27,9 \\
\hline \multicolumn{2}{|c|}{ J u m I a h } & $\mathbf{6 8}$ & $\mathbf{1 0 0 , 0 0}$ \\
\hline
\end{tabular}

Sumber : data primer di olah (2020)

Dari tabel 4.3. di atas menunjukkan frekuensi terbanyak ada pada interval kelas 126-129 dengan jumlah sebesar 30 orang atau 44,1\%. Sedangkan frekuensi paling kecil berada pada interval kelas 118-121 dengan jumlah sebesar 6 orang atau 8,8\%.

Dengan mengacu pada kerangka teori tentang pengkategorian yang telah ditetapkan di bab 3 yakni untuk skor $>(\mathrm{Mi}+\mathrm{Sdi})=$ tinggi, skor antara $(\mathrm{Mi}-\mathrm{Sdi})$ s.d $(\mathrm{Mi}+\mathrm{sdi})=$ sedang dan $(\mathrm{Mi}-\mathrm{Sdi}) \mathrm{ke}$ bawah $=$ rendah , maka dalam penelitian ini diperoleh :

Jumlah item pertanyaan 31 buah, pilihan jawaban 1 s.d 5 .

Nilai tertinggi ideal $=31 \times 5=155$

Nilai terendah $\quad=31 \times 1=31$

$\mathrm{Mi}=1 / 2($ nilai ideal tertinggi + nilai terendah $)$

$=1 / 2(155+31)$

$=93$

Sdi $\quad=1 / 6($ nilai ideal tertinggi - nilai terendah $)$

$=1 / 6(155-31)$

$=20,7$

$\mathrm{Mi}+\mathrm{Sdi}=93+20,7=113,7$

$\mathrm{Mi}-\mathrm{Sdi}=93-20,7=72,3$

Pengelompokan skor motivasi kerja guru dapat dilihat pada tabel berikut :

Tabel: Pengelompokan Skor Motivasi Kerja Guru

\begin{tabular}{|l|l|l|l|l|}
\hline No. & Interval & Frekuensi & Prosentase & Keterangan \\
\hline 1 & $113,7 \mathrm{ke}$ & 68 & 100 & Tinggi \\
2 & atas & 0 & 0 & Sedang \\
3 & 72,3 s.d & 0 & 0 & rendah \\
& $\begin{array}{l}113,7 \\
72,3 \mathrm{ke} \\
\text { bawah }\end{array}$ & & & \\
\hline & Jumlah & 68 & 100 & \\
\hline
\end{tabular}

Berdasarkan perhitungan di atas skor variabel motivasi kerja guru, didapat sebanyak 68 sampel (100\%) berkategori tinggi sehingga dapat disimpulkan secara umum bahwa motivasi kerja guru SMA IT Assalam Martapura tergolong tinggi. 


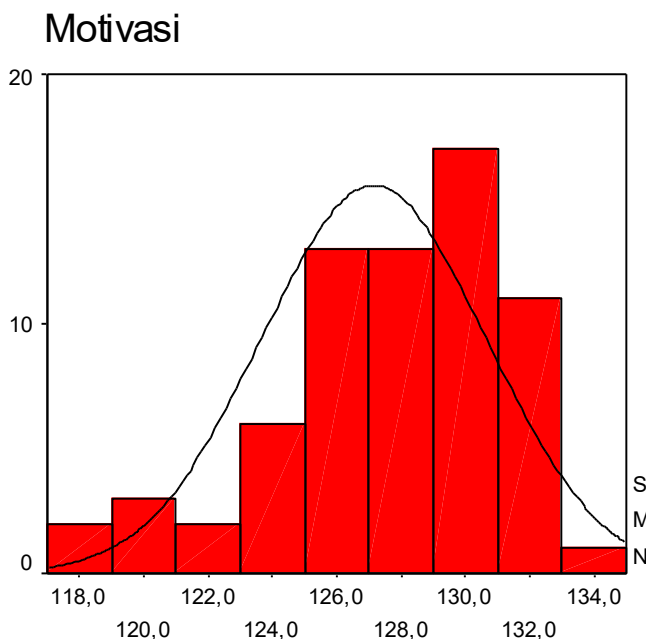

Motivasi

Grafik: Distribusi skor motivasi kerja guru

Motif adalah suatu kontribusi yang lebih, merupakan kekuatan didalam otak yang mengorganisasikan persepsi, apersepsi, intelegensi, dan suatu aksi sebagai cara untuk mengurangi atau mengubah yang tidak menyenangkan. Motivasi atau dorongan adalah suatu pendorong yang dapat mendorong manusia untuk melakukan sesuatu tindakan dorongan (tenaga) atau suatu pendorong tersebut merupakan gerak hati (jiwa) maupun jasmani untuk bertindak atau berbuat atau sesuatu yang melatarbelakangi manusia berbuat sesuatu untuk mencapai keinginannya (tujuan).

Berdasarkan pengujian hipotesis hubungan motivasi kerja guru dengan kemampuan pembelajaran guru SMA IT Assalam Martapura diperoleh diperoleh terdapat hubungan yang positif dan signifikan antara motivasi kerja guru dengan kemampuan pembelajaran guru dengan koefesien korelasi $\mathrm{r}=0,430$.

Atas dasar hasil pengujian hipotesis tersebut dapat diartikan bahwa jika motivasi kerja guru tinggi maka akan berakibat juga pada tingginya kemampuan pembelajaran guru SMA IT Assalam Martapura dan sebaliknya.

\section{Deskripsi Kemampuan Pembelajaran Guru SMA IT Assalam Martapura}

Gambaran kemampuan pembelajaran guru dengan menggunakan fasilitas komputer program SPSS versi 12 dapat diketahui nilai mean, median, standar deviasi, varian, range, serta nilai minimum dan maksimum seperti terlihat pada tabel berikut :
Tabel: Nilai Mean, Median, Standar Deviasi, Varian, Range, Serta Nilai Minimum dan Maksimum Variabel Kemampuan Pembelajaran Guru.

\begin{tabular}{|c|c|c|c|c|c|c|c|}
\hline Variabel & $\mathrm{N}$ & Mean & $\begin{array}{l}\text { Medi } \\
\text { an }\end{array}$ & $\begin{array}{l}\text { Std } \\
\text { dev. }\end{array}$ & $\begin{array}{l}\text { Ran } \\
\text { ge }\end{array}$ & Min & $\begin{array}{c}\text { Ma } \\
\text { ks }\end{array}$ \\
\hline $\begin{array}{c}\text { kemampua } \\
\begin{array}{c}\mathrm{n} \\
\text { pembelajar } \\
\text { an }\end{array}\end{array}$ & 6 & 155,6 & $\begin{array}{c}155, \\
4,68\end{array}$ & $\begin{array}{c}21, \\
0\end{array}$ & $\begin{array}{c}145 \\
, 0\end{array}$ & $\begin{array}{c}166 \\
, 0\end{array}$ \\
\hline
\end{tabular}

Tabel Distribusi Frekuensi Skor Kemampuan Pembelajaran Guru

\begin{tabular}{|l|c|c|c|}
\hline No. & $\begin{array}{c}\text { Interval } \\
\text { Kelas }\end{array}$ & Frekuensi & Persentase (\%) \\
\hline 1 & $145-151$ & 12 & 17,6 \\
\hline 2 & $152-158$ & 41 & 60,3 \\
\hline 3 & $159-166$ & 15 & 22,1 \\
\hline & J u m I a h & $\mathbf{6 8}$ & $\mathbf{1 0 0 , 0}$ \\
\hline
\end{tabular}

Sumber : data primer di olah (2020)

Tabel di atas menunjukkan frekuensi terbanyak ada pada interval kelas 152-158 dengan jumlah sebesar 41 orang atau 60,3\%, sedangkan frekuensi paling kecil berada pada interval kelas 145-151 dengan jumlah sebesar 12 orang atau 17,6 $\%$.

Dengan mengacu pada kerangka teori tentang pengkategorian yang telah ditetapkan di bab 3 yakni untuk skor $>(\mathrm{Mi}+\mathrm{Sdi})=$ tinggi, skor antara (Mi-Sdi) s.d (Mi+sdi) = sedang dan (Mi-Sdi) ke bawah $=$ rendah, maka dalam penelitian ini diperoleh :

Jumlah item instrumen 43 buah, pilihan jawaban 1 s.d 4

Nilai tertinggi ideal $=43 \times 4=172$

Nilai terendah $\quad=43 \times 1=43$

Mi $=1 / 2($ nilai ideal tertinggi + nilai terendah $)$

$$
=1 / 2(172+43)
$$$$
=107,5
$$

Sdi $=1 / 6($ nilai ideal tertinggi - nilai terendah $)$

$=1 / 6(172-43)$

$=21,5$

$\mathrm{Mi}+\mathrm{Sdi}=107,5+21,5=129$

$\mathrm{Mi}-\mathrm{Sdi}=107,5-21,5=86$

Pengelompokan skor kemampuan pembelajaran guru dapat dilihat pada tabel berikut :

Tabel 4.7 Pengelompokan Skor Kemampuan

Pembelajaran Guru

\begin{tabular}{|l|l|l|l|l|}
\hline No. & Interval & Frekuensi & Prosentase & Keterangan \\
\hline 1 & 129 ke a & 68 & 100 & Tinggi \\
2 & 86 s.d 12 & 0 & 0 & Sedang \\
3 & $\begin{array}{l}86 \text { ke } \\
\text { bawah }\end{array}$ & 0 & 0 & Rendah \\
\hline & Jumlah & 68 & 100 & \\
\hline
\end{tabular}


Berdasarkan perhitungan di atas skor variabsebaliknya jika pelaksanaan supervisi dan motivasi kemampuan pembelajaran guru, didapat sebanyak 6\&erja guru rendah maka akan berakibat pada sampel $(100 \%)$ berkategori tinggi sehingga dapaendahnya kemampuan pembelajaran guru.

disimpulkan secara umum bahwa kemampuan pembelajaran guru SMA IT Assalam MartapuikESIMPULAN tergolong tinggi.

Grafik: Distribusi Skor Kemampuan Pembelajaran Guru

\section{Kemampuan Pembelajaran}

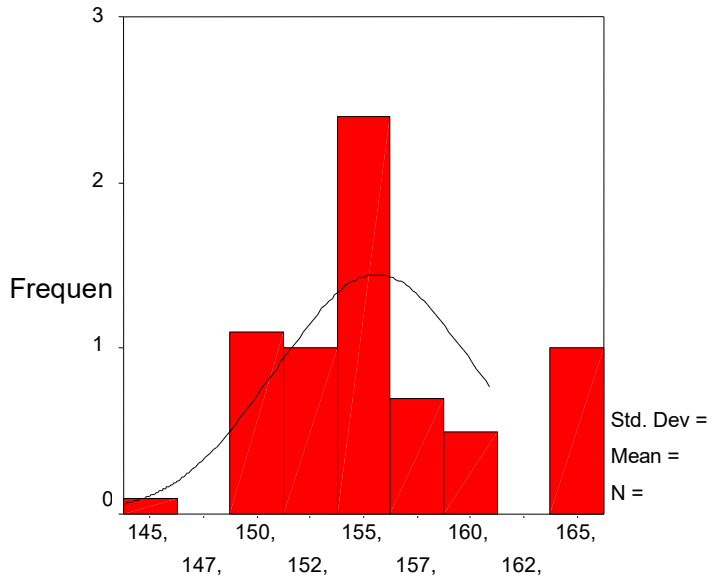

Kemampuan

Pembelajaran adalah proses interaksi peserta didik dengan pendidik dan sumber belajar pada suatu lingkungan belajar. Pembelajaran merupakan bantuan yang diberikan pendidik agar dapat terjadi proses pemerolehan ilmu dan pengetahuan, penguasaan kemahiran dan tabiat, serta pembentukan sikap dan kepercayaan pada peserta didik. Dengan kata lain, pembelajaran adalah proses untuk membantu peserta didik agar dapat belajar dengan baik.

Berdasarkan pengujian hipotesis hubungan pelaksanaan supervisi dan motivasi kerja guru dengan kemampuan pembelajaran guru SMA IT Assalam Martapura diperoleh terdapat hubungan yang positif dan signifikan antara pelaksanaan supervisi dan motivasi kerja guru dengan kemampuan pembelajaran guru dengan koefesien korelasi $\mathrm{R}=0,599$.

Atas dasar hasil pengujian hipotesis secara umum dapat dinyatakan kemampuan pembelajaran guru SMA IT Assalam Martapura sangat dipengaruhi oleh pelaksanaan supervisi dan motivasi kerja guru. Jika pelaksanaan supervisi dan motivasi kerja guru tinggi maka akan berakibat pada tingginya kemampuan pembelajaran guru dan
Berdasarkan hasil penelitian, maka dapat disimpulkan sebagai berikut :

1. Terdapat hubungan yang positif dan signifikan antara pelaksanaan supervisi dengan kemampuan pembelajaran guru SMA IT Assalam Martapura.

2. Terdapat hubungan yang positif dan signifikan antara motivasi kerja guru dengan kemampuan pembelajaran guru SMA IT Assalam Martapura.

3. Terdapat hubungan yang positif dan signifikan secara bersama-sama antara pelaksanaan supervisi dan motivasi kerja guru dengan kemampuan pembelajaran guru SMA IT Assalam Martapura.

\section{DAFTAR PUSTAKA}

Abu Ahmadi,Nur Uhbiyanti, 1991. Ilmu Pendidikan. Jakarta: PT. Rineka Cipta.

Anas Sudijono, 2007. Pengantar Evaluasi Pendidikan. Jakarta: PT. Raja Grafindo Persada.

Anwar Arifin, 2005. Paradigma baru Pendidikan Nasional. Jakarta: Balai Pustaka.

Arikunto,S, 2005. Prosedur Penelitian suatu Pendekatan Praktik. Jakarta: Rineka Cipta.

Asrorun Ni'am Sholeh, 2006. Membangun Profesionalitas Guru Analisis Kronologis atas lahirnya UU Guru dan Dosen. Jakarta: Elsas.

Aunurrahman, 2009. Belajar dan Pembelajaran. Bandung: Alfa Beta.

Departemen Pendidikan Nasional Direktorat Jenderal Pendidikan Dasar dan Menengah Direktorat Tenaga Kependidikan, 2004, Standar Kompetensi Guru sekolah Menengah Atas, Jakarta.

Kunandar, 2007, Guru Profesional Kurikulum KTSP dan Sukses dalam Sertifikasi Guru, Jakarta: PT. Raja Grafindo Persada.

Latifah, 2019. Pola Komunikasi Interpersonal Guru PAI Terhadap Keberhasilan Belajar Siswa Pada MI Assalam Martapura dan SD Muhammadiyah Martapura Kabupaten Banjar. Jurnal Terapung: Ilmu-Ilmu Sosial. Vol. 1 No. 2. September 2019. ISSN: 2656-2928

Miftah Thoha, 2013, Perilaku Organisasi. Jakarta: PT. Raja Grafindo Persada. 
Moh.Uzer Usman, 1990, Menjadi Guru Profesional. Bandung: PT. Remaja Rosda Karya.

Nawawi, Hadari, 1989. Administrasi Pendidikan. Jakarta: CV. Haji Masagung.

Ngalim, Purwanto, 2002. Administrasi Pendidikan. Jakarta: CV. Mutiara.

Soemanto,S. 1987. Psikologi Pendidikan. Jakarta: PT. Bumi Aksara.

Subari,1988. Supervisi Pendidikan. Jakarta: Bumi Aksara.

Sudjana, Nana, 2004. Dasar-dasar Proses Belajar Mengajar. Bandung: Sinar Baru Algensindo.

Sugiyono, 2006. Metode Penelitian Kuantitatif Kualitatif dan R \& D. Bandung: Alpabeta.

Suharsimi Arikunto, 2004. Dasar-dasar Supervisi. Jakarta: PT Rineka Cipta.

Sukadi, 2006. Guru Powerfull Guru Masa Depan. Bandung: Kolbu.

Surya.S, 2005. Dasar-dasar Psikologi untuk Pendidikan di Sekolah. Jakarta: Prima Karya.

Umar Tirtarahardja, 2005. Pengantar Pendidikan. Jakarta: PT. Rineka Cipta. 